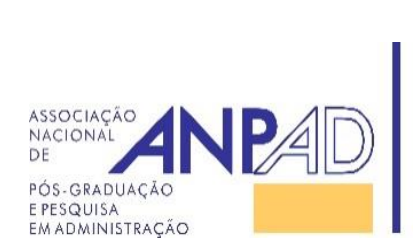

Available online at http://www.anpad.org.br/bar

BAR, Rio de Janeiro, RJ, Brazil, v. 15, n. 3, e180110, 2018 http://dx.doi.org/10.1590/1807-7692bar2018180110

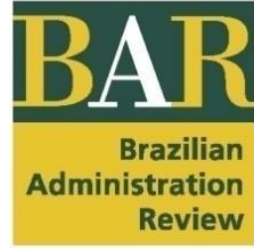

\title{
Editorial:
}

\section{Organizations in an (Anti-)Information Age}

\author{
Carlo Gabriel Porto Bellini \\ Universidade Federal da Paraíba, João Pessoa, PB, Brazil \\ Editor-in-chief \\ Vishal Shah \\ Central Michigan University, Mount Pleasant, MI, USA
}

\begin{abstract}
"(...) governments are having as much success as the Internet in disrupting independent media and determining what information reaches society."
\end{abstract}

Naím and Bennett (2015)

The Internet is a powerful means for people to share information freely and reliably. This is possible due to the Internet's technological infrastructure, governance principles, global reach, and Web 2.0 features that enable on-the-scene, real-time, user-generated content ${ }^{1}$. However, some governments around the world have been censoring online content or building their own regional Internet infrastructure in order to manipulate information, create particular visions of the information world, and ultimately dominate their people (Naím \& Bennett, 2015). Governments may also reframe available online information into useful information for their own intents.

While governments challenge the world of free information in a systematic fashion and with longterm intents, certain individuals also act alone or in groups to manipulate information with short-term goals based on incidental motivations and convenient opportunities. Interestingly, such opportunities emerge in regions where governments do not censor the flow of information in cyberspace, that is, where information democracy is the norm. In such places, certain individuals may want to cause instant damage to other individuals or institutions, and they find opportunities in distributing false information to a large audience given the Internet's reach. Perpetrators engage in information frauds even though oftentimes such frauds can be detected by merely inspecting other relevant sources also available on the Internet. This is the case in a large number of situations, such as when individuals distort a politician's image, a region's socioeconomic indicators, or a company's prospects. Life expectancy of certain false online information is short, but such falsehoods can exert immediate damage to their targets - and there is virtually no penalty for such crimes since legislations regulating the spread of false information on the Internet is largely missing in the democratic world and across countries. 
Though the Internet is commonly recognized as the best tool available to promote quality information inasmuch as quality can be asserted by accuracy, completeness, timeliness and source transparency, in fact it has been used also to spread false information. False information or rumors are extremely powerful to ignite the emergence of an anti-information/anti-intellectual society. Particularly dangerous in cyberspace is the use of evidence-based data to craft false arguments, usually by resorting to incomplete data and ingenious views on correlations; malicious use of factual data has been creatively termed "weapons of math destruction" (O'Neil, 2016). In other words, factual data may be used to create false information and narratives that linger as well as sow discord in the human mind. The information revolution now needs to survive the information wars before a modern version of the Roman catacombs - such as the Deep Web - will be needed for people to share real information safely and accurately ${ }^{2}$.

In this scenario, information processing has become increasingly cognitively demanding as we are confronted with information of mixed quality. We approach information of unknown quality, and it approaches us in everyday contexts especially through our mobile devices and services such as social media. The processing of information stems from the fundamental need to connect and be part of the world around us (Maslow, 1971). However, in addition to the aforementioned deliberate ill-uses of information by third parties, information overload is also a serious threat to our capacity to process information and make good decisions based on it (Eppler \& Mengis, 2004). As a result, also at risk is our expectation of being effective in the digital society - i.e., of making use of technology-mediated information vis-à-vis a purpose and in a systemically healthy way (Bellini, 2018).

Accordingly, as recent events throughout the world have shown, social media platforms are effective means to promote false narratives that amplify bias and try to influence public opinion. There are 3.2 billion social media users in a population of 7.6 billion individuals, of which 2.7 billion are active through their mobile devices (Kemp, 2018). Given the spread of information of mixed quality and the fact that bounded rationality (Simon, 1979) is a permanent limitation for us to deal with information overload, the situation is ripe for opportunists to spread false information - aka fake news - in multiple online platforms. The ability of an individual, a group or state agents to use platforms like social media to spread false information has indeed amplified, as evidenced recently in political campaigning and elections (Allcott \& Gentzkow, 2017; Marchi, 2012). As research by Lazer et al. (2018) points out, the global society needs new safeguarding standards and novel frameworks to approach this problem.

For the specific case of organizations, the availability of false information in society is obviously detrimental. Organizations depend on collecting and processing information to develop strategies and internal routines both at the micro- and the macro-level of analysis - such as when analyzing a job candidate's profile or when guessing about future prospects of the economy prior to a conflict-ridden election process. Organizations have traditionally based their actions on the regular availability of relevant information from known sources, for example when consuming mass media news and industry reports before making decisions. Up until recently, a few major sources (such as the news agencies) were responsible for informing the organizations. Even if each source has its own bias, biases in mainstream information sources are to some degree known by organizations so that a certain level of quality control is possible on consumed information. However, with the Internet, the number of information sources and the real-time production of information exceed an organization's processing capabilities, as virtually all users of an online tool are consumers and contributors of information. Besides, new sources of information emerge constantly, and the quality of a new source may not be inferred quickly, whereas it may be not wise to ignore it at all. Any new source of information may convey weak signals (Ansoff, 1975), which represent potentially extraordinary gains for organizations that explore them first. This makes it even harder for organizations to screen out what is good information, and what is not, in the online world.

The editorial process of a scholarly journal like BAR is also constantly challenged by information wars and uncertainties. BAR's editorial policies and routines are oriented towards identifying and capturing outstanding knowledge available in the academic community, coding it into systematic 
information, acknowledging its usefulness and credibility, and sharing it back to the community. With this in mind, this third issue of volume 15 offers four original research articles and one interview with a renowned scholar. The issue was assembled by past editor-in-chief Dr. Salomão Alencar de Farias with the editorial help of Mrs. Luciane Kato Kiwara. The articles in this issue address a coherent set of ideas towards a better human society based on sound organizational practices and principles - sustainable sharing economy, sustainability indicators for higher education, value co-creation in co-operative organizations, and citizen sourcing in the public sector. We hope this issue contributes to theory and practice in the realm of organizations and in their relationship with the global information society.

\section{Notes}

\footnotetext{
${ }^{1}$ For a rich account on the history and principles of the Internet, we ask the reader to refer to: Leiner, B. M., Cerf. V. G., Clark, D. D., Kahn, R. E., Kleinrock, L., Lynch, D. C., Postel, J., Roberts, L. G., \& Wolff, S. (1997). Brief history of the Internet. Reston, VA, USA: The Internet Society. Retrieved from https://www.internetsociety.org/internet/history-internet/brief-historyinternet/

${ }^{2}$ Here, we do not discuss another interesting issue concerning the access to relevant information: the geographically bounded or user-customized access to information provided by search engines and certain online businesses, a fact that is ignored by a number of online users.
}

\section{References}

Allcott, H., \& Gentzkow, M. (2017). Social media and fake news in the 2016 election. Journal of Economic Perspectives, 31(2), 211-236. https://doi.org/10.1257/jep.31.2.211

Ansoff, H. I. (1975). Managing strategic surprise by response to weak signals. California Management Review, 18(2), 21-33. https://doi.org/10.2307/41164635

Bellini, C.G.P. (2018). The ABCs of effectiveness in the digital society. Communications of the ACM, 61(7), 84-91. https://doi.org/10.1145/3205945

Eppler, M. J., \& Mengis, J. (2004). The concept of information overload: A review of literature from organization science, accounting, marketing, MIS, and related disciplines. The Information Society, 20(5), 325-344. https://doi.org/10.1080/01972240490507974

Kemp, S. (2018). Global digital report 2018. Retrieved from https://wearesocial.com/blog/2018/01/global-digital-report-2018

Lazer, D. M., Baum, M. A., Benkler, Y., Berinsky, A. J., Greenhill, K. M., Menczer, F., Metzger, M. J., Nyhan, B., Pennycook, G., Rothschild, D., Schudson, M., Sloman, S. A., Sunstein, C. R., Thorson, E. A., Watts, D. J., \& Zittrain, J. L. (2018). The science of fake news. Science, 359(6380), 10941096. https://doi.org/10.1126/science.aao2998

Marchi, R. (2012). With Facebook, blogs, and fake news, teens reject journalistic "objectivity". Journal of Communication Inquiry, 36(3), 246-262. https://doi.org/10.1177/0196859912458700

Maslow, A. H. (1971). The farther reaches of human nature. London, UK: Penguin Books.

Naím, M., \& Bennett, P. (2015, February 16). The anti-information age: How governments are reinventing censorship in the $21^{\text {st }}$ century. The Atlantic. Retrieved from https://www.theatlantic.com/international/archive/2015/02/government-censorship-21stcentury-internet/385528/ 
O’Neil, C. (2016). Weapons of math destruction: How big data increases inequality and threatens democracy. New York, NY, USA: Crown Publishers.

Simon, H. A. (1979). Rational decision making in business organizations. American Economic Review, 69(4), 493-513. Retrieved from www.jstor.org/stable/1808698

\section{Authors}

Dr. Carlo Gabriel Porto Bellini

Graduate School of Management, Federal University of Paraíba, Brazil. Campus Universitário I, Jardim Cidade Universitária, 58059-900, João Pessoa, PB, Brazil. E-mail address: bar-eic@ anpad.org.br. https://orcid.org/0000-0001-5809-3172

Dr. Vishal Shah

College of Business Administration, Central Michigan University, Grawn Hall 335, 48859, Mount Pleasant, MI, USA. E-mail address: shah3v@cmich.edu. https://orcid.org/0000-0001-5913-4618 